Produto \& Produção, vol. 6, n. 1, p. 09-23, fev. 2002

\title{
Avaliação do uso de prática de ecodesign nas indústrias do Rio Grande do Sul: um estudo introdutório
}

\author{
Márcia E. Echeveste \\ Tarcísio Abreu Saurin \\ Ângela de Moura Ferreira Danilevicz \\ Programa de Pós-Graduação em Engenharia de Produção - UFRGS \\ Praça Argentina, $n 9$ - sala LOPP - $2^{\circ}$ andar \\ echevest@ppgep.urfrgs.br ; saurin@vortex.ufrgs.br; angelamfd@ppgep.ufrgs.br
}

O momento histórico atual demanda mudanças de comportamento quanto as questões ambientais, fazendo com que dois aspectos fundamentais repercutam diretamente no desenvolvimento de produto das empresas: questões internas de reciclagem e meios de processamento de resíduos e questões externas, como pressão do governo e do mercado. Normas governamentais de preservação ao meio ambiente e a necessidade de manter vantagem competitiva, uma vez que o mercado, principalmente europeu, tem uma grande demanda por produtos verdes. No mercado brasileiro, a questão ambiental ainda não é uma das prioridades, no entanto, para atender ao mercado globalizado, torna-se necessário incluir características "verdes" ao produto, isto é desenvolver produtos considerando questões ambientais nas fases de projeto. Projetos que incluam essas questões são chamados de ecodesign. Poucas pesquisas têm sido desenvolvidas no sentido de verificar o nível de conscientização e o grau de desenvolvimento de produtos com esse enfoque. Esse artigo pretende analisar critérios que podem avaliar a adequação ambiental de empresas e desenvolver um instrumento de coleta de dados capaz de levantar questões relativas ao desenvolvimento de produtos segundo os princípios de ecodesign. No final, são tecidos alguns comentários pertinentes a uma pesquisa realizada com empresas do estado do Rio Grande do Sul e é apresentado o instrumento de coleta de dados.

Palavras-chave: meio-ambiente; ecodesign; desenvolvimento de produto.

All over the world, environmental issues are an increasing concern of governments and companies, and this has required changes in the product development process. From one hand, companies are searching for more effective means to recycle and reuse wastes. On the other hand, there are growing governmental (new and stricter mandatory regulations) and market pressures (demand for green products, mostly in Europe). Even though most of Brazilian companies do not put environmental matters as their priority, they should realize that this attitude constraint their competitiveness in the international market. Take into account eco requirements in the design phase (ecodesign) is a basic and essential step in order to obtain this competitive advantage. Few research studies have investigated the degree of dissemination of products developed under an ecodesign perspective. This paper aims to discuss criteria which can be used to evaluate the environmental compliance of companies from any industrial sector. Also, it is proposed a checklist as a guide for developing products according to ecodesign principles. Finally, it is discussed a survey conducted in a group of industries of the State of Rio Grande do Sul, using the checklist as the data collection tool.

Keywords: environment; ecodesign, product development.

\section{Introdução}

As preocupações com a preservação do meio ambiente são discutidas há algumas décadas. Nos anos 60, a ecologia era uma preocupação apenas de cientistas. A partir dos anos 70, passou a incorporar a pauta das discussões internacionais, especialmente após a ECO72 em Estocolmo e a crise do petróleo em 1973 e 1978. As transformações culturais ocorridas nas décadas de 60 e 70 também tiveram consequiências na relação do homem com o meio ambiente. Nos anos oitenta, principalmente na Alemanha, as empresas 
líderes começaram a se preocupar com o tratamento do que antes era considerado lixo e não era utilizado. Dessa maneira, a proteção ambiental passou a ser vista como um investimento no futuro, o que fez com que esse país atualmente esteja à frente no ecobusiness. Dentre outros dados que refletem essa liderança, pode ser citada a ascensão do partido verde naquele país e o fato de $80 \%$ das grandes e médias empresas terem uma divisão ambiental, contra $20 \%$ em países como a França, por exemplo (Hoffman, 1999).

Atualmente, a nova consciência ambiental tornou-se um dos princípios fundamentais do homem moderno e a gestão ambiental vem se tornando um elemento presente em todos os setores da indústria, especialmente em alguns países desenvolvidos.

Dentre as sistemáticas disponíveis atualmente para a consideração de requisitos ambientais no desenvolvimento de produtos e processos, destaca-se a metodologia do ecodesign. De acordo com Brezet e Van Hemel (1996), a adoção do ecodesign significa considerar os impactos sobre o meio ambiente em todas as decisões de projeto, dispensando a esse assunto a mesma importância atribuída à outros valores industriais tradicionais, tais como lucro, qualidade, estética ou ergonomia do produto. Em alguns casos, pode ser vantajoso que o meio ambiente supere esses valores industriais tradicionais, uma vez que o ecodesign também implica em benefícios econômicos significativos.

O conceito de ecodesign pode ser melhor entendido a partir da discussão de três outros conceitos chave: o de desenvolvimento sustentável, o da redução de resíduos e emissões e o da abordagem do ciclo de vida. O princípio básico do desenvolvimento sustentável é atender as necessidades atuais sem impedir que as gerações futuras atendam as necessidades delas. Assim, o desenvolvimento sustentável tem uma visão mais ampla de meio ambiente, incluindo, também, fatores políticos e sociais que interferem na qualidade de vida e na preservação do meio ambiente. São exemplos desses fatores: o crescimento populacional, a necessidade de aumentar a produção de alimentos, as dívidas dos países de terceiro mundo, a pobreza e a estagnação dos recursos naturais (Brezet e Van Hemel, 1996).

Furtado (1999) apresenta princípios sócio-ecológicos que devem orientar o desenvolvimento sustentável. Esses princípios são os seguintes: as substâncias extraídas da litosfera e os resíduos gerados pelo homem não devem ser acumulados na ecosfera; as condições físicas para a reprodução e diversidade na ecosfera não devem ser deterioradas; o uso de recursos deve ser eficiente e limitado às necessidades humanas, garantindo a oportunidade de escolha para as gerações futuras; os valores culturais das comunidades devem ser respeitados.

A redução de resíduos e emissões é vista como uma das principais medidas práticas para atingir o desenvolvimento sustentável, sendo outro conceito associado ao ecodesign. O princípio que justifica a redução de resíduos e emissões é o de que, na ausência de poluição, não é necessário a limpeza ou o tratamento posterior do meio ambiente. A eliminação, ou limitação dos resíduos e emissões pode ser obtida basicamente por redução na fonte (melhorando produtos e processos) ou pela reutilização dos mesmos (Brezet e Van Hemel, 1996).

Idealmente, deve-se buscar a redução de resíduos e emissões ao longo de toda a vida do produto, desde a extração das matérias-primas até sua disposição final. Em outros termos, pode-se dizer que o objetivo é otimizar todo o ciclo de vida do produto, já visando possibilidades de reciclagem e meios de processamento dos resíduos. A consideração do ciclo de vida do produto também permite identificar os níveis de poluição gerados em cada fase, facilitando o estudo de melhorias (Brezet e Van Hemel, 1996).

As motivações que as empresas têm para implementar o ecodesign vêm de estímulos externos e internos. Dentre os estímulos externos, destacam-se as pressões do governo e as pressões do mercado. As pressões do governo manifestam-se principalmente pela introdução de legislações ambientais cada vez mais rígidas. Além disso, no Brasil, por exemplo, instituições, como o BNDES (Banco Nacional de Desenvolvimento Econômico e Social), já incluíram o impacto ambiental como critério de avaliação para a concessão de financiamentos de projetos (Oliveira, 1999).

Em relação às pressões de mercado, salienta-se a demanda dos consumidores com respeito à processos $\mathrm{e}$ produtos ambientalmente adequados e o aumento da concorrência. Existem dados que comprovam que o mercado internacional tem grande demanda por produtos verdes. Maimon (1995 apud Hoffman, 1999) comenta que nos Estados Unidos, em 1985, apenas 0,5 $\%$ dos produtos introduzidos naquele mercado eram considerados verdes. Em 1990, esse número já era de $9,2 \%$. Em pesquisa realizada pelo Instituto Gallup em vinte e dois países, $53 \%$ dos entrevistados estariam dispostos a pagar mais por produtos que levassem em conta a proteção ambiental. No Brasil esse número estaria em torno de 70 \% (Hoffman, 1999). Em relação à concorrência, Brezet e Van Hemel (1996) consideram que o ecodesign não deve ser encarado como uma ameaça, mas sim como uma oportunidade, atitude que leva a adoção de posturas pró-ativas em relação ao mercado. 
De outra parte, Brezet e Van Hemel (1996) listam os principais estímulos internos que têm levado a adoção do ecodesign como sendo: o senso de responsabilidade social da empresa; a busca de melhoria do nível de qualidade e redução dos custos dos produtos; a melhoria da imagem perante a opinião pública e a necessidade de aumentar a motivação dos funcionários.

De acordo com Furtado (1999), ao optar pelo uso de estratégias ambientais competitivas, as organizações podem estabelecer um de três níveis de ecogerenciamento: (i) limitar-se à conformidade legal; (ii) adotar a postura pró-ativa, antecipando-se e ultrapassando as regulamentações ou; (iii) orientar-se para a sustentabilidade. O primeiro nível deveria ser obrigatório, mas muitas empresas não o atingem devido à falta de fiscalização e punições. O segundo nível é estimulado por legislações mais exigentes e por pressões dos consumidores. Atingir o terceiro nível atuando nos limites da sustentabilidade é mais difícil, uma vez que isso depende da disponibilidade de tecnologias apropriadas e de parcerias com outros segmentos da sociedade e da indústria.

Tendo em vista a disponibilização de recomendações de ordem prática, a UNEP - United Nations Environment Programme - (Brezet e Van Hemel, 1996) sugere que a implementação do ecodesign cumpra oito etapas principais:

Etapa 0 - identificar as implicações do produto que será desenvolvido: devem ser avaliadas as implicações do caráter ecológico do produto, principalmente em termos de marketing e logística. Em relação ao marketing, devem ser destacadas as vantagens técnicas em comparação aos concorrentes e os benefícios do produto em termos de redução do consumo de energia. Nesta etapa também é fundamental que o novo conceito de desenvolvimento de produto adotado, que prima pelo ecodesign, seja disseminado entre todos os envolvidos no processo de projeto;

Etapa 1 - seleção de materiais de baixo impacto ambiental: deve-se buscar o uso de materiais reciclados, passíveis de serem reciclados, não tóxicos para trabalhadores e meio ambiente e que requeiram baixo consumo de energia no processamento;

Etapa 2 - redução de materiais: deve-se buscar, principalmente, utilizar componentes menores (implicam em menor consumo de matéria-prima, menores embalagens, menor geração de resíduos, menos peso para manuseio, estoque e transporte) e avaliar os projetos das embalagens, cujos enchimentos para acomodar o produto devem ser eliminados;

Etapa 3 - otimização de técnicas de produção: o processo deve gerar o mínimo de resíduos e consumir o mínimo de energia possível. Os fornecedores também devem ser avaliados sob a ótica do ecodesign, buscando-se auxiliar tecnicamente aqueles que não aplicam princípios básicos de gestão ambiental;

Etapa 4 - otimização do sistema de distribuição: alguns princípios importantes são a utilização de pallets re-aproveitáveis, o transporte de maiores quantidades para um mesmo destino de uma só vez (reduzindo custos com fretes desnecessários), a compra de materiais de fornecedores próximos ao local de produção e a avaliação da possibilidade de frete marítimo, o qual tem menor impacto ambiental e menor custo;

Etapa 5 - redução do impacto no estágio de uso do produto: dispensar atenção principalmente à orientação aos clientes para que utilizem o produto da forma mais racional e apropriada, além de projetar os componentes tendo em vista a minimização do consumo de energia durante o uso;

Etapa 6 - otimização do tempo de vida do componente: aumentar a confiabilidade e durabilidade dos componentes e orientar o consumidor para que não use o produto em aplicações indevidas, o que pode diminuir a vida útil;

Etapa 7 - otimização do sistema end-of-life: O end-oflife de um produto se refere à tudo que acontece ao mesmo depois que ele foi descartado pelo usuário. Os consumidores devem ser orientados quanto à disposição final do produto e quanto à identificação dos componentes que podem ser reciclados com maior facilidade.

Este estudo foi conduzido tendo em vista dois objetivos principais: (i) analisar os critérios utilizados para diagnóstico da aplicação de práticas de ecodesign na indústria e (ii) propor um instrumento de avaliação da lista de verificação bem como o grau de uso das práticas de ecodesign em um grupo de empresas de diversos setores da indústria do Rio Grande do Sul.

Este artigo está subdividido em 4 seções: apresentação dos objetivos do estudo, o desenvolvimento da lista de verificação, a construção de um instrumento de avaliação e resultados e discussão da aplicação do instrumento em empresas do Rio Grande do Sul estão detalhadas a seguir. 


\section{Desenvolvimento da lista de veri- ficação}

A elaboração do questionário baseou-se principalmente no estudo de Furtado et al. (1999), os quais desenvolveram um conjunto de indicadores para avaliação da adequação ambiental das empresas. Contudo, o estudo de Furtado et al. (1999) não explicita os princípios que embasaram a formulação dos indicadores, o que pode provocar falta de compreensão acerca do significado dos resultados e mesmo desmotivação para a coleta, uma vez que não se entende porque é importante ter um bom desempenho sob a ótica do indicador. Considerando esses aspectos, o presente estudo procurou identificar e explicitar, na lista, os princípios intrínsecos a cada indicador. Assim, foi explicitado, por exemplo, que a exigência das matérias-primas serem leves é importante pois assim torna-se mais fácil o transporte das mesmas desde a extração até a fábrica.

A lista é dividida em oito seções, contendo, no total, quarenta e cinco requisitos ambientais que uma empresa deve cumprir. Os itens da lista estão no questionário apresentado no Anexo. É interessante ressaltar que a lista é uma ferramenta pró-ativa para a gestão ambiental, resumindo os princípios de ecodesign mais importantes e sendo, no seu conjunto, um indicador para a comparação entre diferentes empresas. A Figura 1 apresenta exemplos de requisitos ambientais inseridos no questionário, desenvolvido a partir da lista:

\section{Construção do instrumento de coleta de dados}

Inicialmente, a lista foi adaptada para tornar-se um instrumento de avaliação a ser respondido pelas empresas quanto à adequação do ecodesign em seus projetos de desenvolvimento. É importante ressaltar que, para o bom andamento desse estudo piloto, o pré-teste do questionário foi respondido por um membro do staff da engenharia (desenvolvimento de produto) da empresa-piloto.

Para a execução da pesquisa, a versão final do questionário foi enviada por fax ou e-mail com a opção de resposta por fax ou na versão eletrônica. O endereço do site disponível para preenchimento é (http://www.producao.ufrgs.br/eco2000/ questionario.html). Uma vez preenchido o questionário por meio eletrônico, os dados eram armazenados numa planilha sob controle dos pesquisadores.

Enviou-se para 70 empresas, de médio e grande porte, de diversos setores industriais do Rio Grande do Sul. As mesmas foram selecionadas a partir da listagem da FIERGS (Federação das Indústrias do Estado do Rio Grande do Sul). Essas 70 empresas foram préselecionadas, a partir da opinião de especialistas, levando em consideração a possibilidade de produção de produtos com requisitos ambientais.

Foi também sugerido que o respondente atuasse na área de desenvolvimento de produto, conforme a carta de solicitação de cooperação (Anexo). O percentual de respostas obtidas foi de $10 \%$ (dez porcento), durante o período de maio a agosto de 2000. Com as respostas recebidas, tornou-se possível o levantamento de quais seriam as potenciais informações que comporiam o instrumento de coleta de dados.

\section{Resultados e discussão}

\subsection{Sobre as empresas}

Dentre as empresas que responderam o questionário, três são do setor eletro-eletrônico, duas são do setor metalúrgico e duas do setor de produtos químicos. Todas as empresas são de grande porte e são consideradas representativas no seu ramo de atuação.

\begin{tabular}{|l|l|l|l|l|l|l|}
\hline 2) PROCESSO DE PRODUÇÃo & S & P & N & & NA & NS \\
\cline { 1 - 4 } (a) O processo de produção é atóxico & & & & & & \\
\cline { 1 - 4 } $\begin{array}{l}\text { (b) São adotadas medidas para garantir } \\
\text { o uso racional de água e energia no } \\
\text { processo de extração }\end{array}$ & & & & & & \\
\hline $\begin{array}{l}\text { (c) O processo não gera } \\
\text { subprodutos/resíduos que sejam tóxicos } \\
\text { ou perigosos }\end{array}$ & & & & & & \\
\hline
\end{tabular}

Figura 1 - Exemplos de requisitos de ecodesign incluídos na lista 


\section{Resultados e discussão}

\subsection{Sobre as empresas}

Dentre as empresas que responderam o questionário, três são do setor eletro-eletrônico, duas são do setor metalúrgico e duas do setor de produtos químicos. Todas as empresas são de grande porte e são consideradas representativas no seu ramo de atuação.

O quadro abaixo apresenta os tipos de certificados de sistemas de gestão que as empresas já possuem ou que estão em processo de obtenção.

Quadro 1 - Certificados de sistemas de gestão já obtidos ou em processo de obtenção

\begin{tabular}{|l|c|c|}
\hline \multicolumn{1}{|c|}{ Certificado } & $\begin{array}{c}\text { Certificação já } \\
\text { obtida }\end{array}$ & $\begin{array}{c}\text { Em processo } \\
\text { de certificação }\end{array}$ \\
\hline Série ISO 9000 & 5 empresas & - \\
\hline Série QS 9000 & 1 empresa & - \\
\hline Série ISO $9000+$ QS 9000 & 1 empresa & - \\
\hline Série ISO 14000 & - & 3 empresas \\
\hline
\end{tabular}

Outra constatação diz respeito ao fato de que apenas sete empresas enviaram seus questionários respondidos, o que corresponde a $10 \%$ dos questionários enviados. Essa situação aponta para duas possíveis direções. A primeira delas estaria dentro das estatísticas gerais de retorno de respostas a questionários. Já a segunda direção apontaria para um possível indicativo de que ainda existe falta de conhecimento a respeito de ecodesign na maioria das empresas.

\subsection{Sobre a adoção de princípios de ecodesign}

\subsubsection{Aspectos mercadológicos}

Neste grupo, o total de respostas positivas, quanto a adoção de princípios de ecodesign, correspondeu a $66,7 \%$ do total, enquanto que o cumprimento parcial dos requisitos obteve $24,2 \%$ e o não cumprimento apenas $9,1 \%$. O Quadro 2 apresenta os resultados que cada um dos requisitos obteve:

Dentre os resultados desta seção, destaca-se a boa aceitação dos produtos verdes pelo mercado, o que justifica o fato de que $85,7 \%$ das empresas planejam desenvolver novos produtos com essas características. Contudo, apenas 57,1\% das empresas consideram que possuem pessoal capacitado para desenvolver esses produtos. Tais dados indicam a necessidade de treinamento adicional nessas empresas.

Também é interessante salientar que nem todas as empresas se utilizam das características "verdes" como propaganda: duas empresas utilizam apenas parcialmente e uma não utiliza. As razões que levaram a tal prática não foram investigadas nessa pesquisa.

\subsubsection{Matérias-primas}

Neste grupo, o total de respostas positivas correspondeu a $37 \%$ do total, enquanto que o cumprimento parcial dos requisitos obteve $44,5 \%$ e o não cumprimento obteve 18,5\%. O Quadro 3 apresenta os resultados que cada um dos requisitos obteve:

Quadro 2 - Resultados do grupo de questões relacionadas aos aspectos mercadológicos

\begin{tabular}{|l|c|c|c|c|c|}
\hline & S & P & N & NA & NS \\
\hline $\begin{array}{l}\text { (a) Na fase de conceituação do produto foi realizada uma } \\
\text { pesquisa de mercado }\end{array}$ & 57,1 & 14,3 & 14,3 & 14,3 & - \\
\hline $\begin{array}{l}\text { (b) As características 'verdes' do produto são utilizadas } \\
\text { como propaganda }\end{array}$ & 42,9 & 42,9 & 14,3 & - & - \\
\hline (c) O produto está tendo uma boa aceitação no mercado & 71,4 & 14,3 & & 14,3 & - \\
\hline (d) Existem planos de desenvolver novos produtos verdes & 85,7 & - & 14,3 & - & - \\
\hline $\begin{array}{l}\text { (e) A empresa tem pessoal capacitado para desenvolver } \\
\text { projetos verdes }\end{array}$ & 57,1 & 42,9 & - & - & - \\
\hline
\end{tabular}

$\mathrm{S}=\operatorname{sim} \mathrm{P}=$ parcialmente $\mathrm{N}=$ não $\quad \mathrm{NA}=$ não se aplica $\mathrm{NS}=$ não sabe 
Quadro 3 - Resultados do grupo de questões relacionadas às matérias-primas

\begin{tabular}{|c|c|c|c|c|c|}
\hline & $\mathbf{S}$ & $\mathbf{P}$ & $\mathbf{N}$ & NA & NS \\
\hline $\begin{array}{l}\text { (a) São adotadas medidas para minimizar o impacto da } \\
\text { extração de matérias-primas sobre o ecossistema }\end{array}$ & 42,9 & 28,6 & 28,6 & - & - \\
\hline (b) As matérias-primas são renováveis & - & 71,4 & 28,6 & - & - \\
\hline $\begin{array}{l}\text { (c) As matérias-primas são leves, facilitando o transporte } \\
\text { até a fábrica }\end{array}$ & 42,9 & 42,3 & 14,3 & - & - \\
\hline $\begin{array}{l}\text { (d) São adotadas medidas para garantir o uso racional } \\
\text { de água e energia no processo de extração }\end{array}$ & 57,1 & 28,6 & 14,3 & - & - \\
\hline
\end{tabular}

$\mathrm{S}=\operatorname{sim} \mathrm{P}=$ parcialmente $\mathrm{N}=$ não $\mathrm{NA}=$ não se aplica $\mathrm{NS}=$ não sabe

Os resultados dessa seção indicam que as medidas para preservação das matérias-primas não têm sido completamente implementadas, uma vez que o percentual de respostas assinaladas com parcialmente ou não foi alto $(63 \%)$. Em parte, isso talvez possa ser atribuído a restrições tecnológicas, uma vez que alguns produtos ainda não dispõem de matériasprimas alternativas de menor impacto ambiental.

Um outro dado que merece atenção é o que mostra que 28,6\% das empresas utilizam somente matériasprimas não-renováveis. Pode-se, então, questionar o caráter verde dos referidos produtos.

\subsubsection{Processo de produção}

A partir dos resultados visualizados no Quadro 4, se observa que existe grande potencial para otimização do processo de produção nas empresas estudadas, uma vez que $70,4 \%$ das respostas foram assinaladas com parcialmente ou não. É particularmente grave o dado que demonstra que em $85,7 \%$ dos casos são gerados subprodutos / resíduos tóxicos. De outra parte, é positivo que em $85,7 \%$ das empresas exista reutilização, ao menos parcial, das sobras de materiais.

\subsubsection{Produto}

O Quadro 5 sintetiza o percentual de respostas relativas ao produto final. Dos valores apresentados, $55 \%$ das respostas foram assinaladas como se o produto atendesse parcialmente ou não atendesse as "questões verdes".

Dentre os destaques positivos, podem ser citados os seguintes resultados: a) as respostas à questão (h), que indicam que todos os produtos analisados utilizaram, ao menos parcialmente, materiais reciclados; b) as respostas à questão (1), que revelam que existe grande potencial para incorporação de características verdes à produtos comuns.

No que diz respeito aos destaques negativos, salientam-se os dados que revelam que os produtos "verdes" têm desempenho inferior ao similar. As respostas às questões (b), (c), (i) e (j), deixam clara essa tendência. Tais resultados talvez possam ser explicados pelo fato de que as tecnologias "verdes" são relativamente recentes, reforçando a necessidade de pesquisas nessa área.

Quadro 4 - Resultados do grupo de questões relacionadas ao processo de produção

\begin{tabular}{|c|c|c|c|c|c|}
\hline & $\mathbf{S}$ & $\mathbf{P}$ & $\mathbf{N}$ & NA & NS \\
\hline $\begin{array}{l}\text { (b) São adotadas medidas para garantir o uso racional de água e } \\
\text { energia no processo de extração }\end{array}$ & 42,9 & 14,3 & 14,3 & - & 28,6 \\
\hline $\begin{array}{l}\text { (c) O processo não gera subprodutos/resíduos que sejam tóxicos ou } \\
\text { perigosos }\end{array}$ & 14,3 & 71,4 & 14,3 & - & - \\
\hline $\begin{array}{l}\text { (d) As sobras de materiais são reutilizadas no próprio processo de } \\
\text { produção original, ou em outro processo qualquer no âmbito da empresa }\end{array}$ & 14,3 & 71,4 & 14,3 & - & - \\
\hline
\end{tabular}

$\mathrm{S}=\operatorname{sim} \mathrm{P}=$ parcialmente $\mathrm{N}=$ não $\mathrm{NA}=$ não se aplica $\mathrm{NS}=$ não sabe 
Quadro 5 - Resultados do grupo de questões relacionadas ao produto

\begin{tabular}{|c|c|c|c|c|c|}
\hline & $\mathbf{S}$ & $\mathbf{P}$ & $\mathbf{N}$ & NA & NS \\
\hline (a) É atóxico & 57,1 & 42,9 & - & - & - \\
\hline (b) Tem maior vida útil do que o similar & 28,6 & 14,3 & 42,9 & 14,3 & - \\
\hline (c) É mais fácil de desmontar, remontar e consertar do que o similar & 28,6 & 14,3 & 42,9 & 14,3 & - \\
\hline (d) É modulável & 14.3 & 28.6 & 28.6 & 28.6 & \\
\hline $\begin{array}{l}\text { (e) É atualizável (flexível para incorporar inovações de versões mais } \\
\text { novas) }\end{array}$ & 16.7 & 33,7 & 16,7 & 33,3 & - \\
\hline (f) É adequado ao uso (fácil manuseio) & 71,4 & 28,6 & - & - & - \\
\hline (g) É de fácil instalação & 28,6 & 42,9 & - & 28,6 & - \\
\hline (h) É elaborado com material reciclado, total ou parcialmente & - & 100 & - & - & - \\
\hline $\begin{array}{l}\text { (i) Funciona com baixo consumo de água e energia, em comparação } \\
\text { com os similares }\end{array}$ & 28,6 & - & 57,1 & - & 14,3 \\
\hline (j) Usa o mínimo de embalagem, em comparação com os similares & 14,3 & 28,6 & 42,9 & 14,3 & - \\
\hline (k) A embalagem é reciclável, em comparação com os similares & 28,6 & 14,3 & 14,3 & 28,6 & 14,3 \\
\hline (I) O produto representa uma evolução de um projeto anterior & 71,4 & 14,3 & - & 14,3 & - \\
\hline (m) A empresa tem potencial para desenvolver novos projetos verdes & 85,7 & 14,3 & - & - & - \\
\hline $\begin{array}{l}\text { (n) A empresa preocupa-se em desenvolver novos projetos voltados } \\
\text { ao ecodesign nos próximos anos }\end{array}$ & 85,7 & 14,3 & - & - & - \\
\hline
\end{tabular}

$\mathrm{S}=\operatorname{sim} \mathrm{P}=$ parcialmente $\mathrm{N}=$ não $\mathrm{NA}=$ não se aplica $\mathrm{NS}=$ não sabe

\subsubsection{Marketing ambiental}

Em relação à utilização de marketing ambiental, $57,9 \%$ das respostas foram assinaladas com parcialmente ou não.

O destaque positivo desse grupo é o percentual de respostas à questão (a), demonstrando maturidade tanto das empresas quanto dos usuários para a importância da divulgação e do incentivo ao uso de produtos "verdes", ou seja, existe um seguimento de consumidores dispostos a adquirir produtos com características "verdes", ainda que tais produtos tenham preço superior ao similar "não-verde".

Em contrapartida, os destaques negativos desse grupo são as respostas à questão (c), as quais indicam que as empresas ainda não dispõem de uma estrutura satisfatória de coleta de embalagens e produtos no pós-uso.

\subsubsection{Manejo ambiental}

Em resposta às questões formuladas sobre manejo ambiental, 48,8\% das respostas foram assinaladas com parcialmente ou não atendendo a esse quesito. Os destaques negativos nesse grupo são os seguintes (i) de acordo com as respostas à questão (b) $85,8 \%$ das empresas fazem (ao menos parcialmente) despejos em aterros; (ii) conforme as respostas à questão (a), somente $28,6 \%$ das empresas praticam a prevenção total de resíduos na fonte de produção. De outra parte, o destaque positivo é o fato de nenhuma empresa deixa de fazer reciclagem primária ou secundária.

Quadro 6 - Resultados do grupo de questões relacionadas ao marketing ambiental

\begin{tabular}{|l|c|c|c|c|c|c|}
\hline & S & P & N & & NA & NS \\
\cline { 1 - 2 } $\begin{array}{l}\text { (a) As características verdes do } \\
\text { produto têm valor de mercado }\end{array}$ & 85,7 & - & 14,3 & & - & - \\
\hline $\begin{array}{l}\text { (b) Pratica o direito de acesso } \\
\text { público à informação ambiental }\end{array}$ & 28,6 & 28,6 & 14,3 & & 14,3 & 14,3 \\
\cline { 1 - 2 } $\begin{array}{l}\text { (c) Há estrutura de coleta de } \\
\text { embalagens e produtos no pós-uso }\end{array}$ & - & 42,9 & 57,1 & & - & - \\
\hline
\end{tabular}

Quadro 7 - Resultados do grupo de questões relacionadas ao manejo ambiental

\begin{tabular}{|l|c|c|c|c|c|c|}
\hline & S & P & N & & NA & NS \\
\cline { 1 - 3 } $\begin{array}{l}\text { (a) Pratica a prevenção de } \\
\text { resíduos na fonte de produção }\end{array}$ & 28,6 & 71,4 & - & & - & - \\
\hline $\begin{array}{l}\text { (b) Inexistem despejos (tóxicos } \\
\text { ou não) em aterros }\end{array}$ & 14,3 & 42,9 & 42,9 & & - & - \\
\hline (c) Inexiste incineração & 71,4 & - & 28,6 & & - & - \\
\hline $\begin{array}{l}\text { (d) É feita reciclagem primária } \\
\text { na própria empresa }\end{array}$ & 57,1 & 42,9 & - & & - & - \\
\hline $\begin{array}{l}\text { (e) É feita reciclagem } \\
\text { secundária fora da empresa }\end{array}$ & 42,9 & 57,1 & - & & - & - \\
\hline $\begin{array}{l}\text { (f) São adotados padrões } \\
\text { elevados de saúde e segurança } \\
\text { no trabalho }\end{array}$ & 85,7 & - & - & & - & 14,3 \\
\cline { 1 - 2 }
\end{tabular}




\subsubsection{Conformidade ambiental}

Os requisitos relativos a este grupo obtiveram o melhor desempenho global, uma vez que apenas 30,6 $\%$ das respostas foram assinaladas com parcialmente ou não.

Os destaques positivos nesse grupo são os seguintes: (i) as respostas à questão (a), as quais indicam que todas as empresas cumprem integralmente as legislações ambientais vigentes em todos os níveis; (ii) as respostas às questões $(\mathrm{c}),(\mathrm{d}),(\mathrm{e}),(\mathrm{f}),(\mathrm{g})$ e (h), as quais demonstram que, de modo geral, as empresas não parecem ser grandes poluidoras.

O fato de nenhuma empresa possuir o selo verde pode ser atribuído a constatação de que tais selos normalmente são certificados de primeira parte, ou seja, concedidos por organismos setoriais. Além disso, conforme já apresentado, três empresas estão em processo de certificação pelas normas da série ISO 14000 , as quais proporcionam um certificado de maior valor do que qualquer selo verde disponível no mercado de certificação.

\subsubsection{Comunicação ambiental}

A resposta à questão única dessa seção indica que as empresas ainda carecem de melhor divulgação de sua política e prática ambiental. Embora não tenha sido avaliado, é fundamental que tais políticas e práticas sejam divulgadas tanto em nível interno quanto externo às empresas.

No primeiro caso, a divulgação é pré-requisito para o comprometimento e qualificação dos funcionários em relação à boa gestão ambiental, enquanto que no segundo caso, a divulgação tem papel de marketing e mesmo de disponibilizar subsídios para que os clientes escolham seus fornecedores.

Quadro 8 - Resultados do grupo de questões relacionadas à conformidade ambiental

\begin{tabular}{|c|c|c|c|c|c|}
\hline & S & $\mathbf{P}$ & $\mathbf{N}$ & NA & NS \\
\hline $\begin{array}{l}\text { (a) A empresa atende a legislação ambiental, } \\
\text { em nível federal, estadual e municipal }\end{array}$ & 100 & - & - & - & - \\
\hline (b) O produto possui selo verde ou similar & - & - & 100 & - & - \\
\hline $\begin{array}{l}\text { (c) Os processos e produtos são inofensivos a } \\
\text { camada de ozônio }\end{array}$ & 71,4 & 14,3 & 14,3 & - & - \\
\hline $\begin{array}{l}\text { (d) Os processos e produtos não poluem o mar } \\
\text { e rios }\end{array}$ & 71,4 & - & 28,6 & - & - \\
\hline $\begin{array}{l}\text { (e) Inexistem prejuízos a zonas úmidas (florestas, } \\
\text { matas e mangues) de importância internacional }\end{array}$ & 85,7 & - & - & 14,3 & - \\
\hline (f) Inexiste prejuízo a biodiversidade & 42,9 & 28,6 & - & 14,3 & 14,3 \\
\hline $\begin{array}{l}\text { (g) Inexiste uso de POPs (poluentes orgânicos } \\
\text { persistentes) }\end{array}$ & 71,4 & - & 14,3 & 14,3 & - \\
\hline $\begin{array}{l}\text { (h) Inexiste comercialização de espécies em } \\
\text { extinção }\end{array}$ & 42,9 & - & 14,3 & 42,9 & - \\
\hline
\end{tabular}

$\mathrm{S}=\operatorname{sim} \mathrm{P}=$ parcialmente $\mathrm{N}=$ não $\mathrm{NA}=$ não se aplica $\mathrm{NS}=$ não sabe

Quadro 9 - Resultados do grupo de questões relacionadas à comunicação ambiental

\begin{tabular}{|l|c|c|c|c|c|c|}
\hline & S & P & N & & NA & NS \\
\cline { 1 - 2 } $\begin{array}{l}\text { A empresa divulga sua política e práticas } \\
\text { ambientais }\end{array}$ & 28,6 & - & 71,4 & & - & - \\
\hline
\end{tabular}

$\mathrm{S}=\operatorname{sim} \mathrm{P}=$ parcialmente $\mathrm{N}=$ não $\mathrm{NA}=$ não se aplica $\mathrm{NS}=$ não sabe

\subsubsection{Comparação entre os itens avaliados no questionário}

A Figura 2 apresenta um resumo dos resultados da aplicação do questionário, facilitando a comparação entre os diferentes tipos de requisitos ambientais analisados.
De acordo com a Figura 2, as empresas têm os melhores desempenhos nos requisitos relacionados à conformidade ambiental e aos aspectos mercadológicos. De outra parte, os resultados não foram tão bons em seções relacionadas à implementação prática de técnicas de produção limpa, como nas seções sobre produto, matérias-primas e 


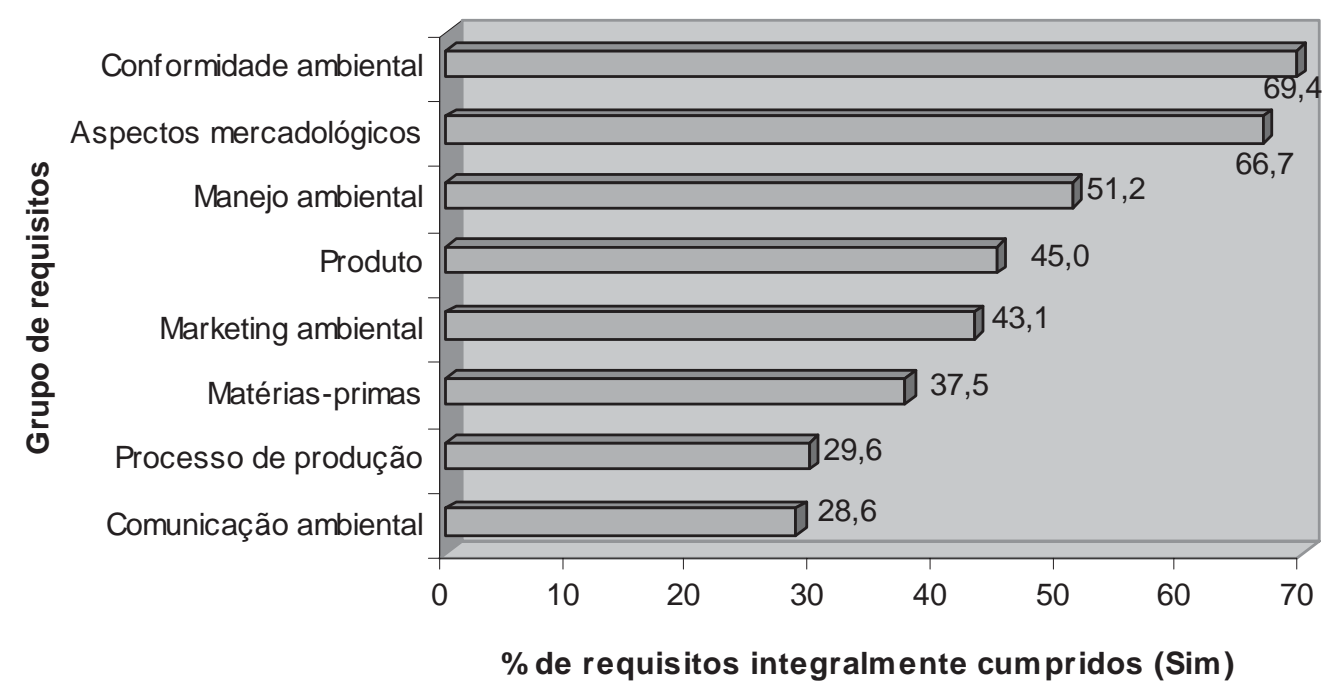

Figura 2 - Percentual de requisitos obtidos em cada seção do questionário

processo de produção. Além disso, os requisitos quanto ao uso racional de energia, contidas nos grupos de questões 2, 3 e 4 (Matérias-Primas; Processo de Produção; e Produto, respectivamente) apresentaram baixo percentual de respostas assinaladas com sim. Deste modo, observa-se que, mesmo dentre um grupo de empresas que pode ser considerado de exceção na indústria brasileira, a implementação do ecodesign ainda está em fase incipiente. Maiores investimentos em tecnologias limpas e capacitação de pessoal parecem ser necessidades evidentes.

\section{Considerações finais}

O objetivo principal desse artigo foi analisar critérios que podem avaliar a adequação ambiental de empresas e baseado nestes desenvolver um instrumento de coleta de dados para levantamento de questões pertinentes a ecodesign. Esse instrumento foi testado em empresas de médio e grande porte do estado do Rio Grande do Sul. O nível de respostas foi da ordem de $10 \%$, fazendo com que não se possa inferir sobre os resultados, devido ao baixo percentual de retorno e a não representatividade da amostra em relação à população.

Contudo, algumas tendências puderam ser identificadas dentre as empresas pesquisadas. Podese citar como destaques positivos: (i) as empresas planejam desenvolver novos produtos verdes; (ii) as empresas reutilizam, pelo menos, parcialmente, as sobras de materiais; (iii) as empresas consideram que as características verdes do produto têm valor de mercado.
Dentre os destaques negativos obtidos através das empresas pesquisadas, salientam-se os seguintes itens: (i) existe uma carência de pessoal capacitado para desenvolver novos projetos verdes; (ii) um número reduzido de empresas preocupa-se com a utilização de matérias-primas renováveis em seus processos produtivos.

Constata-se, também, que as empresas consideram importante adotar características verdes aos seus produtos (item 4.2.5), no entanto não exploram iniciativas ambientais (4.2.8).

Salienta-se, que o instrumento pode ser considerado como uma evolução dos modelos propostos anteriormente sobre avaliação e diagnóstico da situação das industrias quanto ao ecodesign. Duas contribuições podem ser destacadas: (i) a geração e disponibilização de um documento em HTML, o que facilita o acesso do respondente; (ii) um melhor esclarecimento em relação aos princípios dos requisitos de ecodesign.

Como melhoria no instrumento de coleta de dados sugere-se incluir uma questão que investigue as motivações e dificuldades para as empresas adotarem processos de produção mais limpos e produtos com ecodesign.

Recomenda-se que esse instrumento seja replicado em uma amostra maior e que seja validado estatisticamente. Os resultados diagnosticariam o conhecimento e a aplicação de projetos voltados ao meio ambiente e colaborariam, tanto para futuros trabalhos de pesquisa, quanto para a condução de novos projetos de 
desenvolvimento de produtos "verdes" para a sociedade. A partir de resultados mais representativos seria possível prever tendências do ecodesign no Rio Grande do Sul e extensivo a outras populações-alvo.

\section{Referências bibliográficas}

BREZET, H.; VAN HEMEL, C. Ecodesign: a promising approach to sustainable production and consumption, 1996. Disponível na INTERNET: www.inventas.no/ELCE_2000/toura.htm (site acessado em 12/05/99)

FURTADO, J.; et al. Prevenção de resíduos na fonte \& economia de água e energia, 1999. Disponível na INTERNET: www.vanzolini.org.br/areas/desenvolvimento/producaolimpa (site acessado em 12/05/99)

HOFFMAN, V. Estratégia e ecologia: um estudo de caso. Produção, v.8, n.2, 1999.

OLIVEIRA, F.B. Implementação e prática da gestão ambiental: discussão e estudo de caso. Programa de Pós-Graduação em Engenharia de Produção, UFRGS, 1999. Dissertação de Mestrado.

\section{Agradecimentos}

Agradecemos à Prof ${ }^{a}$ Lia Buarque de Macedo Guimarães, Ph.D., CPE, pela sua consciente preocupação com a preservação do meio-ambiente e estímulo à realização de pesquisas nessa área,e acima de tudo, pelo conhecimento repassados para a elaboração desse artigo.

\section{Anexo 1 - Carta de apresentação da pesquisa}

Prezado Senhor,

Precisamos da sua colaboração para uma pesquisa de avaliação da implementação de quesitos ambientais no desenvolvimento de produtos.

Estamos enviando em anexo um questionário destinado a avaliar o grau de adoção da técnica de ecodesign pelas indústrias da região, com vistas a subsidiar futuros trabalhos de pesquisa na área. $\mathrm{O}$ ecodesign consiste em avaliar matérias-primas, produtos e processos sob o ponto de vista ambiental, de modo a manter a empresa ambientalmente adequada.

Recomendamos que a pessoa que preencha esses dados seja preferencialmente o gerente do desenvolvimento de produtos ou gerente industrial.

O questionário preenchido pode ser enviado via email (eco2000@ppgep.ufrgs.br) ou fax (316-4007).

Atenciosamente,

Dierê Fernandez

(pesquisadora do Programa de Pós-Graduação em Engenharia de Produção)

Quaisquer esclarecimentos, favor entrar em contato pelo telefone 316-3490 (ou por e-mail). 


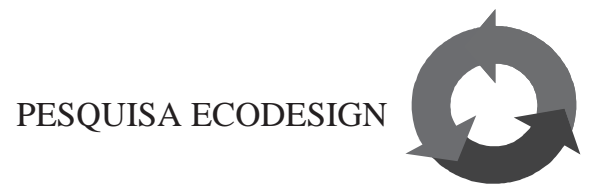

\section{UNIVERSIDADE FEDERAL DO RIO GRANDE DO SUL}

PROGRAMA DE PÓS-GRADUAÇÃO EM ENGENHARIA DE PRODUÇÃO

Prezados Senhores

Este questionário destina-se a realizar um levantamento do grau de adoção da técnica de ecodesign pelas indústrias da região, com vistas a subsidiar futuros trabalhos de pesquisa na área. O ecodesign consiste em avaliar matériasprimas, produtos e processos sob o ponto de vista ambiental, de modo a manter a empresa ambientalmente adequada.

Caso exista interesse, a empresa pode receber o relatório com a tabulação dos dados do levantamento. O questionário é dividido em três seções e as respostas devem basear-se no produto que melhor represente a incorporação de considerações ambientais, desde a extração da matéria-prima até o uso (PRODUTO VERDE).

Recomendamos que a pessoa que preencha esses dados seja preferencialmente o gerente do desenvolvimento de produtos ou Gerente industrial.

Porto Alegre, 5 de maio de 2000.

Atenciosamente,

Lia Buarque Guimarães (coordenador da pesquisa)

\section{DADOS GERAIS DA EMPRESA}

(1) Ramo:

(2) Telefone / fax:

(3) Nome e cargo do respondente:

(4) E-mail:

\section{CARACTERIZAÇÃO DO PRODUTO}

(1) Qual o seu principal produto verde?.....

(2) Qual a (as) características que tornam este produto verde?

(3) Que sugestões de pesquisa sua empresa demanda na área de produtos verdes?.......

(4) Que tipo de certificação a sua empresa já possui?

( ) ISO 9000

( ) QS 9000

( ) ISO 14000

( ) Outra. Qual?.

( ) Em andamento para certificação. Qual? 
20 Produto \& Produção, vol. 6, n. 1, p. 09-23, fev. 2002

3. LISTAGEM PARA AUTO-AVALIAÇÃO DA ADEQUAÇAO AMBIENTAL DA EMPRESA

\begin{tabular}{|c|c|c|c|c|c|}
\hline & $\mathbf{s}$ & $\mathbf{P}$ & $\mathbf{N}$ & NA & NS \\
\hline \multicolumn{6}{|l|}{ 1) ASPECTOS MERCADOLÓGICOS } \\
\hline \multicolumn{6}{|l|}{$\begin{array}{l}\text { (a) Na fase de conceituação do produto foi realizado uma pesquisa de } \\
\text { mercado. }\end{array}$} \\
\hline \multicolumn{6}{|l|}{ (b) As características 'verdes' do produto são utilizadas como propaganda } \\
\hline \multicolumn{6}{|l|}{ (c) O produto está tendo uma boa aceitação no mercado } \\
\hline \multicolumn{6}{|l|}{ (d) Existem planos de desenvolver novos produtos verdes } \\
\hline (e) A empresa tem pessoal capacitado para desenvolver projetos verdes & & & & & \\
\hline
\end{tabular}

\section{2) MATÉRIAS- PRIMAS}

(a) São adotadas medidas para minimizar o impacto da extração de matérias-primas sobre o ecossistema

(b) As matérias-primas são renováveis

(c) As matérias-primas são leves, facilitando o transporte até a fábrica

(d) São adotadas medidas para garantir o uso racional de água e energia no processo de produção

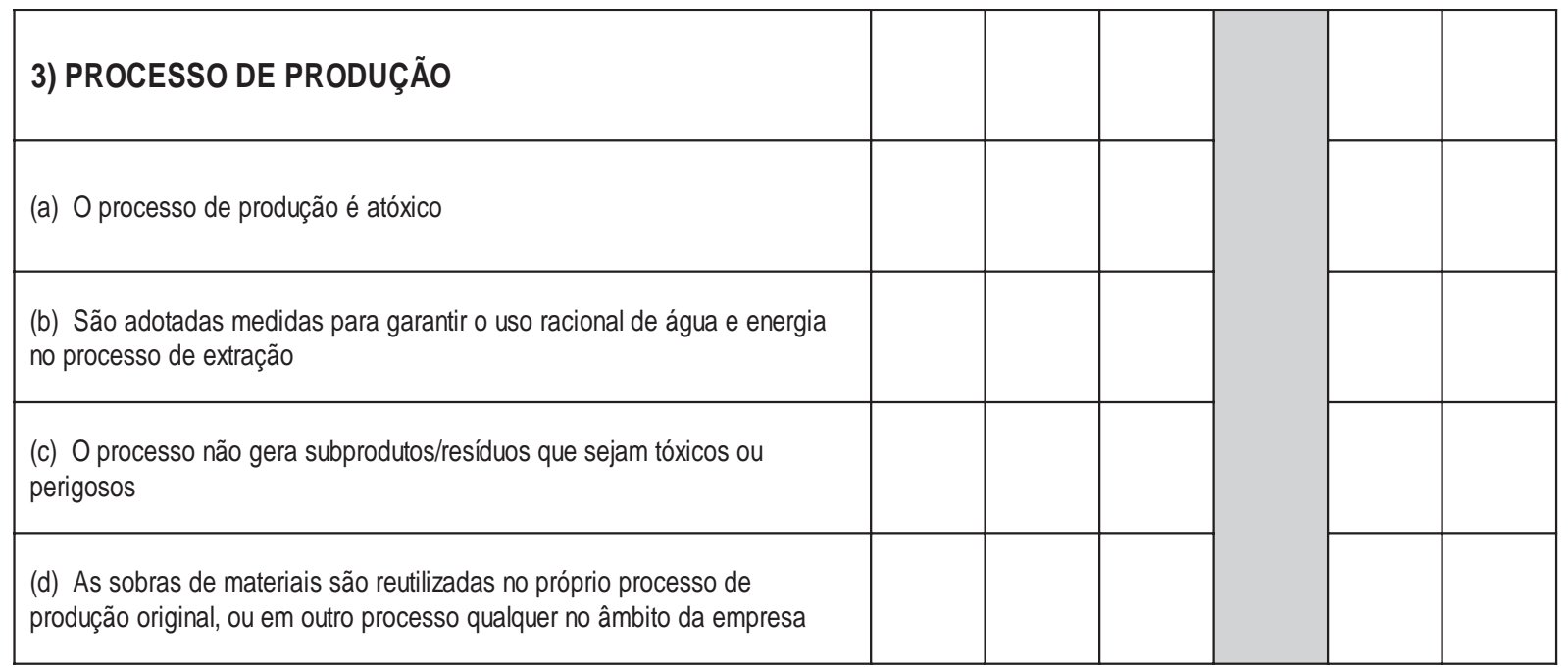


Echeveste, M. E. ; Saurin, T. A.; Danilevicz, A. de M. F. - Avaliação do uso de prática de ecodesign ...

\begin{tabular}{|c|c|c|c|c|c|}
\hline & $\mathrm{S}$ & $\mathbf{P}$ & $\mathbf{N}$ & NA & NS \\
\hline \multicolumn{6}{|l|}{ 4) PRODUTO } \\
\hline \multicolumn{6}{|l|}{ (a) É atóxico } \\
\hline \multicolumn{6}{|l|}{ (b) Tem maior vida útil do que o similar } \\
\hline \multicolumn{6}{|l|}{ (c) É mais fácil de desmontar, remontar e consertar do que o similar } \\
\hline \multicolumn{6}{|l|}{ (d) É modulável } \\
\hline \multicolumn{6}{|l|}{ (e) É atualizável (flexível para incorporar inovações de versões mais novas) } \\
\hline \multicolumn{6}{|l|}{ (f) É adequado ao uso (fácil manuseio) } \\
\hline \multicolumn{6}{|l|}{ (g) É de fácil instalação } \\
\hline \multicolumn{6}{|l|}{ (h) É elaborado com material reciclado, total ou parcialmente } \\
\hline \multicolumn{6}{|l|}{$\begin{array}{l}\text { (i) Funciona com baixo consumo de água e energia, em comparação com } \\
\text { os similares }\end{array}$} \\
\hline \multicolumn{6}{|l|}{ (j) Usa o mínimo de embalagem, em comparação com os similares } \\
\hline \multicolumn{6}{|l|}{ (k) A embalagem é reciclável, em comparação com os similares } \\
\hline \multicolumn{6}{|l|}{ (I) O produto representa uma evolução de um projeto anterior } \\
\hline \multicolumn{6}{|l|}{ (m) A empresa tem potencial para desenvolver novos projetos verdes } \\
\hline $\begin{array}{l}\text { (n) A empresa preocupa-se em desenvolver novos projetos voltados ao } \\
\text { ecodesign nos próximos anos }\end{array}$ & & & & & \\
\hline
\end{tabular}

\section{5) MARKETING AMBIENTAL}

(a) O produto tem valor de mercado

(b) Pratica o direito de acesso público à informação ambiental

(c) Há estrutura de coleta de embalagens e produtos no pós-uso

\section{6) MANEJO AMBIENTAL}

(a) Pratica a prevenção de resíduos na fonte de produção

(b) Inexistem despejos (tóxicos ou não) em aterros

(c) Inexiste incineração

(d) É feita reciclagem primária na própria empresa

(e) É feita reciclagem secundária fora da empresa

(f) São adotados padrões elevados de saúde e segurança no trabalho
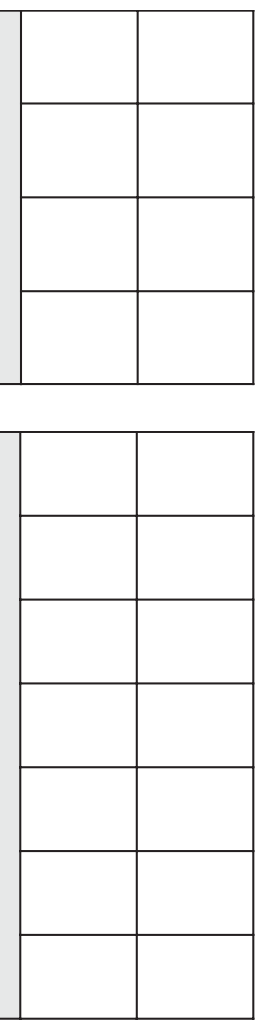


\begin{tabular}{|c|c|c|c|c|c|}
\hline & $\mathrm{S}$ & $\mathbf{P}$ & $\mathbf{N}$ & NA & NS \\
\hline \multicolumn{6}{|l|}{ 7) CONFORMIDADE AMBIENTAL } \\
\hline \multicolumn{6}{|c|}{$\begin{array}{l}\text { (a) A empresa atende a legislação ambiental, em nível federal, estadual e } \\
\text { municipal }\end{array}$} \\
\hline \multicolumn{6}{|l|}{ (b) O produto possui selo verde ou similar } \\
\hline \multicolumn{6}{|c|}{ (c) Os processos e produtos são inofensivos a camada de ozônio } \\
\hline \multicolumn{6}{|l|}{ (d) Os processos e produtos não poluem o mar e rios } \\
\hline \multicolumn{6}{|c|}{$\begin{array}{l}\text { (e) Inexistem prejuízos a zonas úmidas (florestas, matas e mangues) de } \\
\text { importância internacional }\end{array}$} \\
\hline \multicolumn{6}{|l|}{ (f) Inexiste prejuízo a biodiversidade } \\
\hline \multicolumn{6}{|l|}{ (g) Inexiste uso de POPs (poluentes orgânicos persistentes) } \\
\hline (h) Inexiste comercialização de espécies em extinção & & & & & \\
\hline
\end{tabular}

\section{(8) COMUNICAÇÃO AMBIENTAL}

(a) A empresa divulga sua política e práticas ambientais

Obrigado por colaborar!

Se desejar os resultados desta pesquisa, deixe seu e-mail ou endereço para que possa recebê-los.

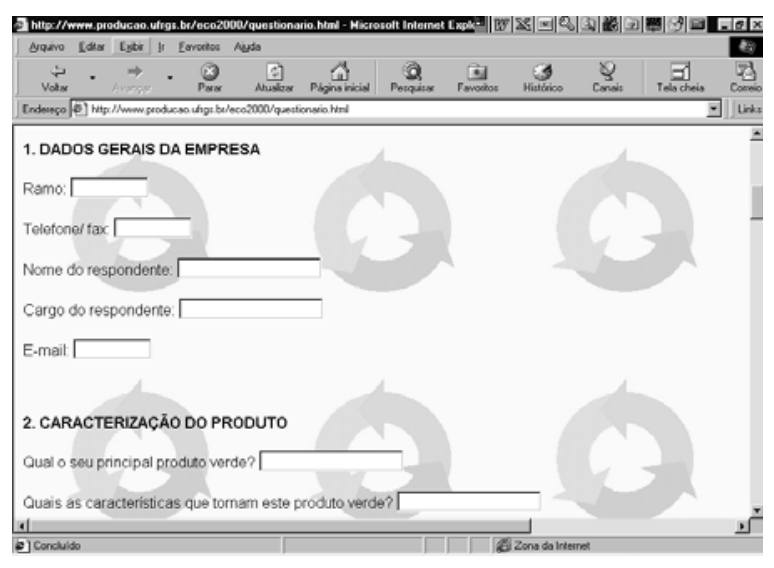

Figura 4 - Questionário em html: dados da empresa e

Figura 5 - Questionário em html: início da auto-avaliação caracterização do produto 


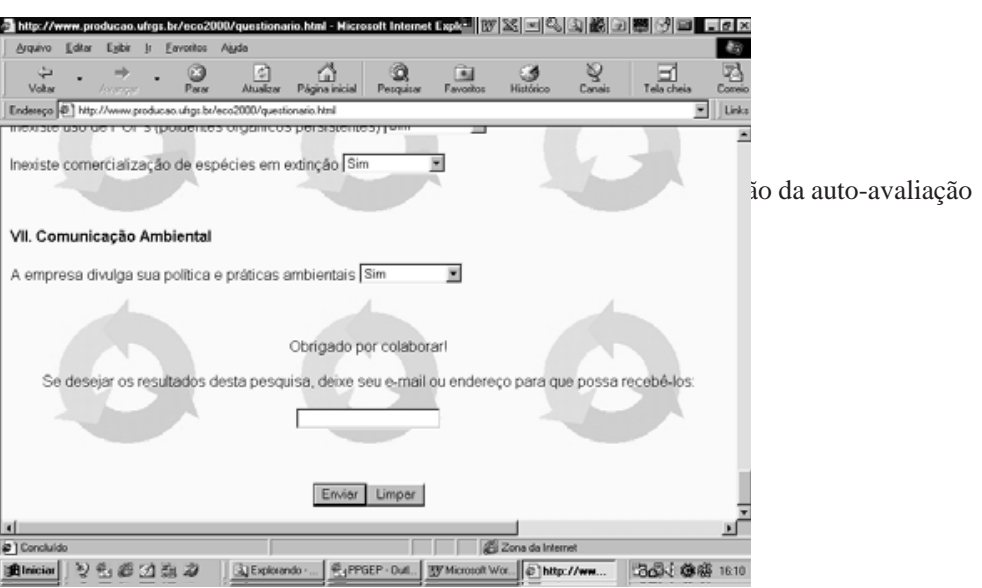

Figura 8 - Questionário em html: continuação da auto-avaliação 